\title{
Aventuras estudantis no CEFD: sonhos, trajetórias e desencantos no diretório acadêmico
}

\author{
Student adventures at CEFD: dreams, trajectories, and disenchantments in the academic directory
}

Aventuras estudiantiles en CEFD: sueños, trayectorias y desencantos en el directorio académico

\author{
Ana Cristina Zimmermann ${ }^{\mathrm{I}}$, Ana Lúcia de Lima Santos ${ }^{\mathrm{II}}$
}

\begin{abstract}
Resumo
A memória é uma das maiores riquezas que podemos compartilhar. No momento em que o CEFD comemora 50 anos consideramos importante registrar nosso reconhecimento a esta instituição. O objetivo principal deste artigo é contribuir com o registro histórico do CEFD, descrevendo a perspectiva estudantil a partir das experiências de atuação no Diretório Acadêmico (DACEFD) nos anos de 1992 a 1994. Os relatos apresentam as ações realizadas seguidos de reflexões correlatas, e estão pautados na memória pessoal das autoras, bem como em documentos de acervo pessoal. A defesa da universidade pública tem sido uma luta constante, renovada a cada geração, o que permite que ainda existam oportunidades de acesso ao ensino público e de qualidade. A formação política durante a graduação acompanha e fortalece a formação acadêmica, que ultrapassa o âmbito das disciplinas curriculares e se concretiza também pela oportunidade da diferença, do diálogo, da experiência do espaço público e democrático.
\end{abstract}

Palavras-chave: movimento estudantil; democracia; formação política; universidade pública; CEFD

\begin{abstract}
Memory is one of the greatest riches that we can share. When CEFD celebrates 50 years, we consider it important to register our recognition of this institution. The main objective of this article is to contribute to the historical record of CEFD, describing the student perspective from the experiences of acting in the Academic Directory (DACEFD) in the years 1992 to 1994. The reports present the actions taken followed by related reflections, and are based on the authors' memory and on personal collection documents. The public university's defense has been a constant struggle, renewed by each generation, which allows opportunities to access public and quality education. Political formation during graduation accompanies and strengthens academic training that goes beyond the scope of curricular disciplines. Academic qualification is also materialized by the opportunity for difference, dialogue, and the experience of the public and democratic space.
\end{abstract}

Keywords: student movement; democracy; political education; public university; CEFD

\footnotetext{
${ }^{\text {I }}$ Universidade de São Paulo - Endereço: Av. Prof. Mello Moraes, 65 - Cidade Universitária - CEP: 05508-030 - São Paulo - SP - e-mail: ana.zimmermann@usp.br

II Prefeitura Municipal de Jaraguá do Sul - e-mail: 1 d8241@ @araguadosul.sc.gov.br
} 


\section{Resumen}

La memoria es una de las mayores riquezas que podemos compartir. Cuando CEFD cumple 50 años, consideramos importante registrar nuestro reconocimiento a esta institución. El objetivo principal de este artículo es contribuir al registro histórico del CEFD, describiendo la perspectiva de estudiantes a partir de las experiencias de actuación en el Directorio Académico (DACEFD) en los años 1992 a 1994. Los informes presentan las acciones realizadas seguidas de reflexiones, y son basado en la memoria personal de las autoras así como en documentos de colección personal. La defensa de la universidad pública ha sido una lucha constante, renovada por cada generación, que permite oportunidades de acceso a una educación pública y de calidad. La formación política durante la graduación acompaña y fortalece la formación académica que va más allá del ámbito de las disciplinas curriculares, y se materializa también en la oportunidad de la diferencia, el diálogo y la experiencia del espacio público y democrático.

Palabras clave: movimiento estudiantil; democracia; formación política; Universidad pública

"O passado não reconhece o seu lugar: está sempre presente."

Mário Quintana

\section{Introdução}

Este artigo tem a intenção de descrever nossa experiência com o Movimento Estudantil (ME) nos anos de 1992 a 1994 no Centro de Educação Física e Desportos (CEFD) da Universidade Federal de Santa Maria (UFSM). Cursávamos a Licenciatura Plena em Educação Física e neste período o curso da UFSM revezava com a Escola de Educação Física e Esportes da USP os primeiros lugares no ranking nacional de graduação e pós-graduação em Educação Física (UFSM, 2020). Eram tempos turbulentos, o País experimentava seus primeiros anos de abertura democrática, com uma nova Constituição após longo período sob ditadura militar. O curso de Educação Física havia passado por uma reforma curricular recente buscando ultrapassar seu caráter técnico esportivo ao ampliar o diálogo com a pedagogia e as ciências sociais e humanas, inserindo novas disciplinas inspiradas pelos debates epistemológicos dos anos 1980 (SOUZA, COUTO; MARIN, 2014). Além da ampliação da formação para um período mínimo de quatro anos, acirra-se o debate entre ciências naturais e humanas e a discussão que posteriormente culminou na formação específica para licenciatura e bacharelado. A formação profissional na área gerava amplas e calorosas discussões, das quais tivemos a oportunidade de participar ativamente. $\mathrm{O}$ ambiente político nacional não era tranquilo, com muitas greves, e nossos semestres letivos nunca seguiam um calendário supostamente normal. Para dar uma ideia, entre 1990 e 1995 tivemos quatro greves das universidades federais, sendo que em 1991 foram 107 dias de paralisação, uma das mais longas da 
história (SEDUFSM, 2020). Isso significava frequentemente aulas durante o verão escaldante de Santa Maria, mas também um convite ao debate político. Tanto a situação do ensino público quanto a da Educação Física formavam o contexto ideal para sonhos e desencantos de uma juventude engajada.

O objetivo principal deste texto é, portanto, contribuir com o registro histórico do CEFD, descrevendo a perspectiva estudantil a partir das experiências de atuação no Diretório Acadêmico (DACEFD) nos anos de 1992 a 1994. Neste período estivemos diretamente envolvidas com o DACEFD, Diretório Central de Estudantes (DCE) e com a Executiva Nacional dos Estudantes de Educação Física (ExNEEF). Durante estas três gestões o DACEFD teve configurações diferentes e grupos renovados, portanto não ocupávamos sempre as mesmas funções. Consideramos os registros históricos de grande importância, em especial no momento em que o CEFD comemora seus 50 anos, mantendo-se como um centro de referência tanto na formação de professoras/es como de pesquisadoras/es na construção da Educação Física brasileira. Felizmente os diferentes rumos da historiografia têm demonstrado a importância do acesso a realidades negligenciadas, ampliando a discussão acerca das identidades. Como ressalta Le Goff (1990, p.410) "A memória é um elemento essencial do que se costuma chamar identidade, individual ou coletiva, cuja busca é uma das atividades fundamentais dos indivíduos e das sociedades de hoje, na febre e na angústia”. Este é, portanto, um texto que versa também sobre construção de identidade.

A descrição aqui apresentada está baseada principalmente em experiências pessoais, assim reconhecemos as limitações de algumas informações, em um registro que não se pretende universal. Trata-se apenas de uma perspectiva de um determinado momento histórico, que pode ser atravessada por tantas outras. Alguns dados estão pautados em documentos de arquivo pessoal. Felizmente conservamos, as duas, o apego a fontes que imaginamos que "um dia podem ser importantes". Desta forma temos alguns originais de panfletos, que eram feitos à mão e depois xerocados, projetos datilografados, crachás de eventos, e alguns arquivos digitais com o registro das ações realizadas durante o período em que estivemos no DACEFD. Os arquivos digitais estão em disquete, o armazenador de dados da época, portanto inacessíveis no momento. Precisaria uma visita ao museu da tecnologia para acessar estes arquivos. Quem é deste século pode procurar na internet para saber do que se trata. Para uma ideia rápida a capacidade de armazenamento de dados era inferior a uma fotografia que tiramos no celular atualmente. Naquela época não existia internet aberta como atualmente, nem google, nem word e tantos outros programas, plataformas e aplicativos de armazenagem e compartilhamento de informações, e pouquíssimos eram os computadores pessoais naquele contexto. Estrategicamente o DACEFD tinha um integrante possuidor de recursos high tech (um computador), e conhecimentos preciosos na área. No 
CEFD o primeiro computador, para uso de estudantes, foi instalado durante o período ao qual se refere este texto. Tratava-se de um computador para aproximadamente 500 estudantes, disponibilizado na nova “sala do computador". Inicialmente nem houve problemas de gerenciamento porque ninguém sabia usar e poucos eram os recursos. Praticamente uma máquina de escrever mais sofisticada que precisava de uma impressora. Após algum tempo o uso se popularizou e outros equipamentos se tornaram disponíveis. No DACEFD tentávamos manter todos os registros e projetos, ou fisicamente, com o recurso do papel carbono (outra busca de internet aconselhada para a juventude), ou em arquivos digitalizados quando possível. Infelizmente não conseguimos acesso a todo este material, especialmente em momento pandêmico, mas temos aqueles guardados com carinho em acervo pessoal. Compartilhamos, portanto, ao longo do texto algumas imagens destes registros, majoritariamente fotos, rascunhos, projetos, jornais e panfletos. Assim reforçamos que este texto não tem a intenção de apresentar dados exaustivos ou uma sequência linear de fatos, mas utiliza dos recursos disponíveis no momento para compartilharmos um pouco da experiência, registrada sobretudo na memória das autoras. Tais experiências foram fortes e transformadoras, e constituem elementos essenciais de nossa formação no CEFD. Embora se trate de um recorte histórico específico a partir de experiências pessoais, esta não é uma história individual, mas elaborada em um coletivo, que nos acompanha ao longo de nossa trajetória como professoras de Educação Física em instituições públicas.

\section{Contexto}

Por sua posição geográfica, a cidade de Santa Maria é conhecida como "coração do Rio Grande". Dadas estas condições, a UFSM congrega estudantes de todas as regiões do estado, principalmente do interior. Este era um dos elementos mais interessantes na configuração de estudantes. Tínhamos colegas das mais longínquas regiões, do centro às fronteiras, de cidades pequenas e médias. Com colegas aprendíamos sobre a geografia, sotaques e costumes diversos. Percebemos nossas próprias peculiaridades e elaboramos uma identidade quando entramos em contato com a diferença (SILVA, HALL, WOODWARD, 2000). Por exemplo, em toda a região de fronteira sul se fala "leite quente", como se escreve, com "e" no final. Para alguns isso era engraçado, para outras era o correto. Ao conhecermos tantas outras formas de falar a mesma língua a noção de correto pareceu inadequada. Entendemos que a desconstrução e o questionamento das noções de certo e errado, ou mesmo de verdade, é um aprendizado importante que pode se dar nos mínimos detalhes, desde que sejamos capazes de assumir uma postura dialógica, tal qual sugere Paulo Freire (1996) na construção da autonomia. 
Entrar na universidade pública era uma imensa conquista e grande oportunidade. Desde o início de nossa atuação na política estudantil a defesa da universidade pública permaneceu como a principal bandeira. Também porque constantemente ameaçada pelos valores neoliberais defendidos pelos governos de José Sarney, "Fora Collor", Itamar Franco e Fernando Henrique, sucessivamente (ALMEIDA, 2005).

O Centro Acadêmico era composto por um grupo que variava de três a quinze participantes aproximadamente. Esta composição era sempre flexível e acompanhava a agenda do período letivo, tanto de avalições quanto de eventos. Início do ano, de gestão e grandes eventos o grupo era maior, em épocas de provas e exames o grupo ficava reduzido. Alguns temas eram mais atraentes que outros. Uma oscilação bastante frequente no ME. Pelo baixo número de estudantes disponíveis para algumas atividades, o grupo se revezava nas representações - em conselhos da diretoria, reitoria, DCE, entre outros - e acabamos compreendendo o funcionamento de todos os setores. Esta situação também é recorrente no ME em diferentes instituições e períodos históricos.

A proposta de atuação, embora sem muita certeza acerca de nomenclaturas e linhas teóricas, era certamente dialógica e impulsionada pela efervescência do movimento crítico dos anos 1980. Discutíamos de tudo, com os recursos disponíveis: colegas que participavam de grupos de pesquisa, colegas do DCE ou de outros cursos, uma miscelânea de referenciais, autores da Educação Física tanto do próprio CEFD como de outras instituições, e mesmo nomes como Walter Benjamin, Jürgen Habermas e Bertold Brecht, misturados com poetas como Mario Quintana, e grupos musicais como Legião Urbana. Colegas de grupos de estudo ou de outras instituições compartilhavam textos, a caro custo xerocados e discutidos. É bom ressaltar que sem internet ou digitalização, possuir fisicamente uma fonte de conhecimento e informação era algo extremamente precioso.

O coletivo de estudantes que participou mais ativamente do centro acadêmico naquele período era majoritariamente formado por mulheres. Além do cuidado com vários aspectos pouco reconhecidos em estruturas de gestão, a proposta de trabalho era a de um grupo horizontalizado em suas relações, com atribuições distintas por aproximação e especificidade, mas com decisões coletivas em todas as instâncias.

A relação com colegas de curso oscilava ao sabor da pauta ou do tipo de evento realizado. Tivemos assembleias com mais de 200 participantes e outras apenas com integrantes do DACEFD. Eventos com mais de mil participantes e outros que nem chegaram a acontecer. Reuniões do DACEFD com mais de vinte integrantes e muitas com duas ou três. Mantínhamos um jornalzinho, feito à mão e depois xerocado como meio de comunicação (Figura 1). Também elaborávamos panfletos distribuídos em situações específicas para mobilização intensiva (Figura 2). A relação com a direção e coordenação era com frequência conflituosa, entretanto em alguns projetos específicos parcerias interessantes se 
estabeleceram. Após uma sequência de eventos bem sucedidos ampliaram-se as possibilidades de diálogo, mas apesar de resguardados os limites do respeito, estávamos sempre na mira do "eu avisei". Aprendemos muito com todas as circunstâncias de conflito nas quais precisávamos tomar posição e defender ideias publicamente.

Figura 1: Originais e reprografia de jornais do DACEFD

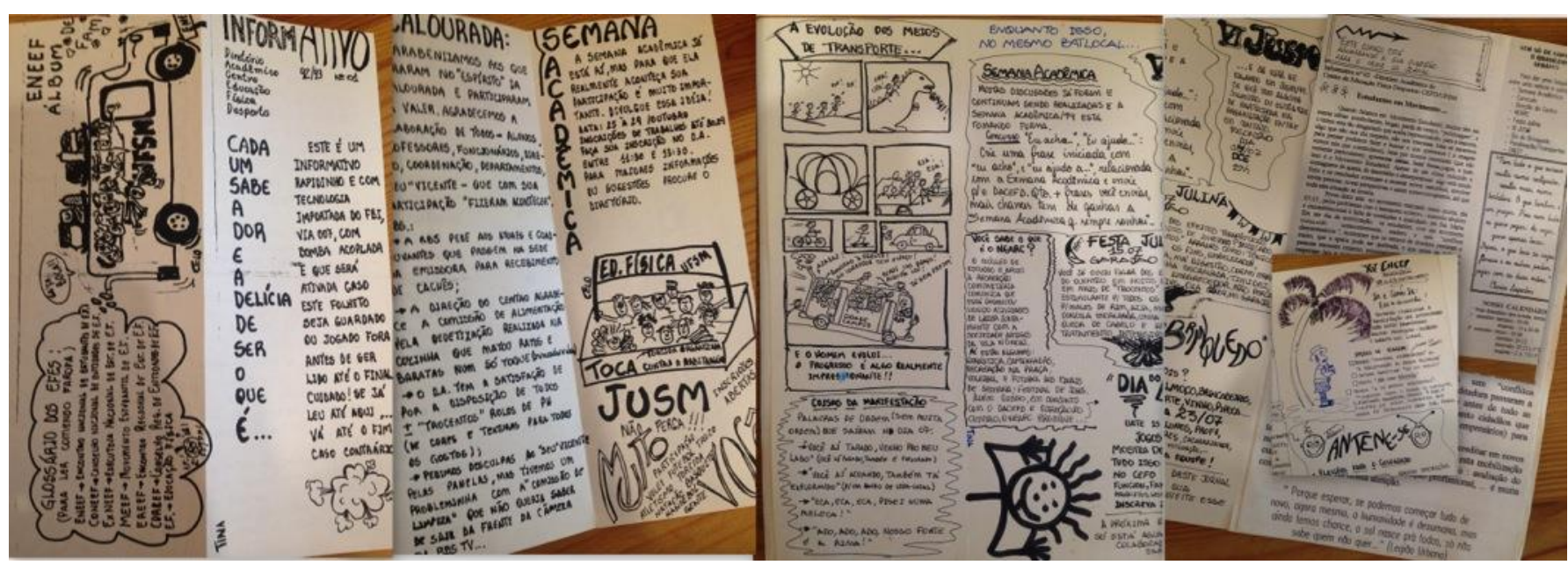

Fonte: Acervo pessoal das autoras

Figura 2: Rascunhos e panfletos distribuídos em diferentes ocasiões

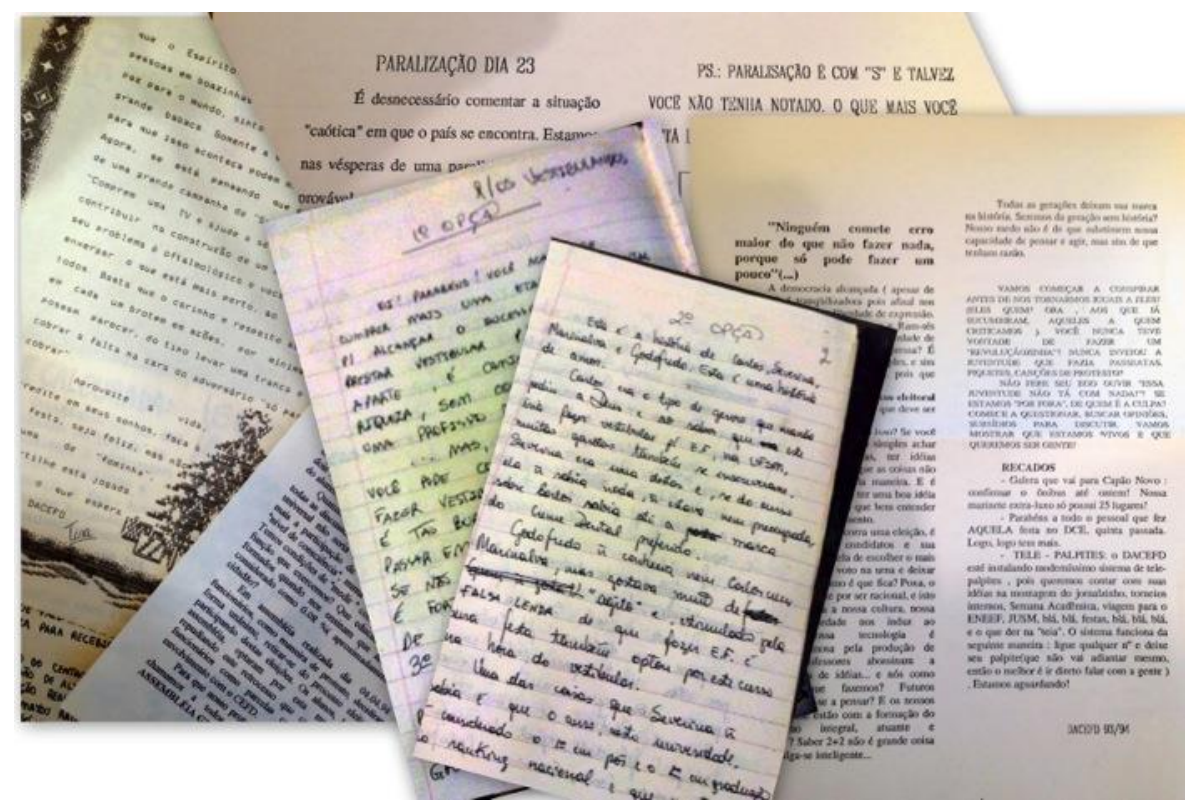

Fonte: Acervo pessoal das autoras 


\section{Principais ações realizadas e resultados alcançados}

Iniciamos com fôlego, com discussões sobre a estrutura do grupo, sobre objetivos e trajetórias possíveis. As atividades do DACEFD envolviam a representação estudantil nas diferentes instâncias universitárias, proposição de discussões acerca de questões acadêmicas e da gestão universitária, participação em diferentes instâncias representativas como DCE e ExNEEF, organização de eventos com diferentes objetivos, tais como Semana Acadêmica, Jogos Universitários, festas diversas, entre outros. Entre os temas mais frequentes na proposição de mobilizações estavam a defesa da universidade pública, o preço das passagens e a qualidade do transporte público, as condições da moradia estudantil e do Restaurante Universitário, e questões curriculares. Muitas foram as passeatas pedindo a baixa da passagem de ônibus, por exemplo, daquelas que classicamente terminam com perseguição da polícia e correria de cachorros. A luta pelo voto universal nas eleições da direção do centro também gerou grandes discussões.

Realizávamos a cada ano pesquisas entre estudantes para identificar questões de interesse, tanto para eventos como para debates. Havia também a preocupação com a convivência e reorganização do espaço, sala e antessala no corredor de entrada do prédio, abaixo da escadaria principal, para que se tornasse mais acolhedor não só para estudantes diretamente envolvidos no DACEFD. Durante o período foram colocados armários para uso de estudantes, conseguidos com doações, mesa de pingue-pongue (que não durou muito por causa do barulho), jogos de tabuleiro, cadeiras, poesias e modestos grafites nas paredes. A intenção era incentivar o convívio, pois imaginávamos que isso poderia aproximar estudantes também na discussão de problemas comuns. Entre tanta movimentação, neste artigo iremos descrever rapidamente três tipos de ações diferentes realizadas neste período, a fim de ilustrar as atividades: a representação estudantil e o diálogo nacional, um evento acadêmico, um evento esportivo.

Logo no primeiro ano, quase por acaso (um panfleto recebido pelo correio em período de férias) e com muita dificuldade, participamos de um encontro da ExENEEF em Maceió e com isso começamos a entender a organização nacional de estudantes de Educação Física. Além de uma sequência infinita de siglas terminadas em EEF, abria-se um universo de relações. Foi a motivação para pensarmos as possibilidades de organizarmos um ônibus com estudantes do CEFD para os Encontros Nacionais de Estudantes de Educação Física (ENEEFs). Lembrando que toda a articulação à distância precisava ser feita por carta ou telefone (fixo, portanto “orelhão" ou aquele da instituição, cujo acesso só era possível mediante autorização da direção). Em certo momento de nossa história descobrimos o maravilhoso mundo mágico dos projetos. Após cursar uma disciplina sobre planejamento e organização de eventos 
elaborávamos projetos ininterruptamente, com todos os detalhes, dentro das normas, datilografados ou impressos, protocolados (Figura 3).

Figura 3: O maravilhoso mundo mágico dos projetos (projetos originais)

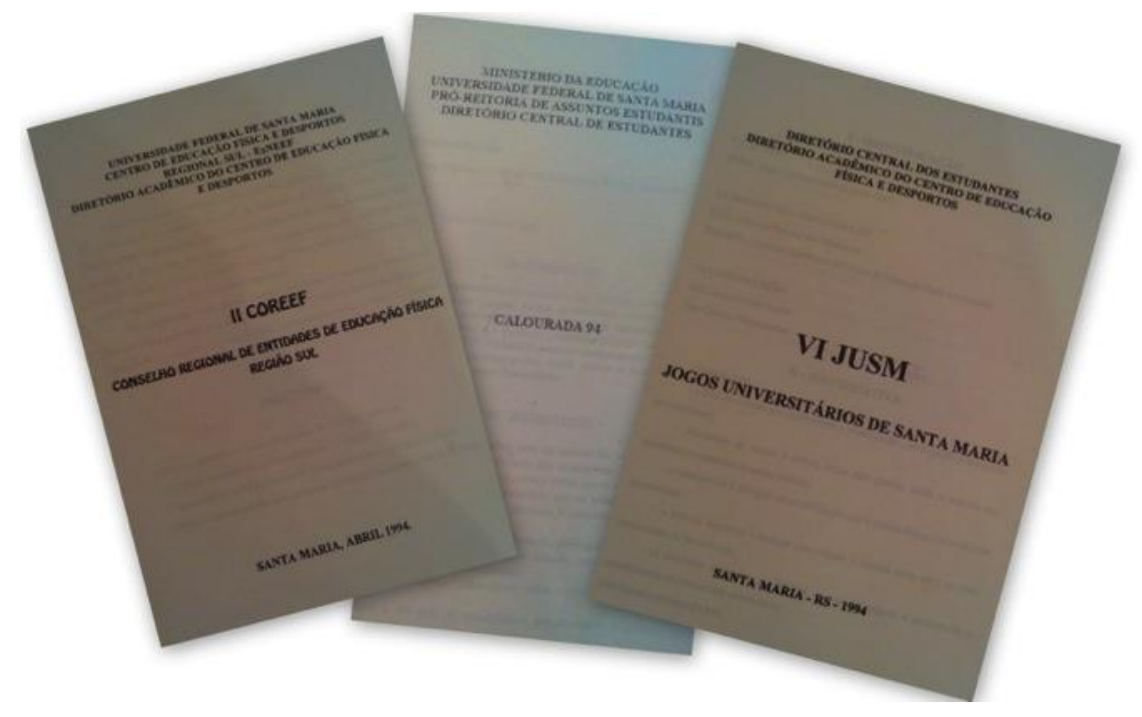

Fonte: Acervo pessoal das autoras

Os eventos eram importantes para aproximar estudantes, criar pontos de contato, campos de discussão, bem como gerar renda para outras atividades. Assim, uma festa junina e várias "baladas" compartilhadas com as engenharias, veterinária ou pedagogia nos porões do DCE ajudaram a arrecadar verba para fretar um ônibus que possibilitou a mobilidade de um grupo grande de estudantes para participar do XIV ENEEF em Goiânia no ano de 1993 (Figuras 4, 5 e 6), e posteriormente do XV ENEEF, em João Pessoa, 1994.

Figura 4: Ônibus com estudantes do CEFD/UFSM em direção ao XIV ENEEF

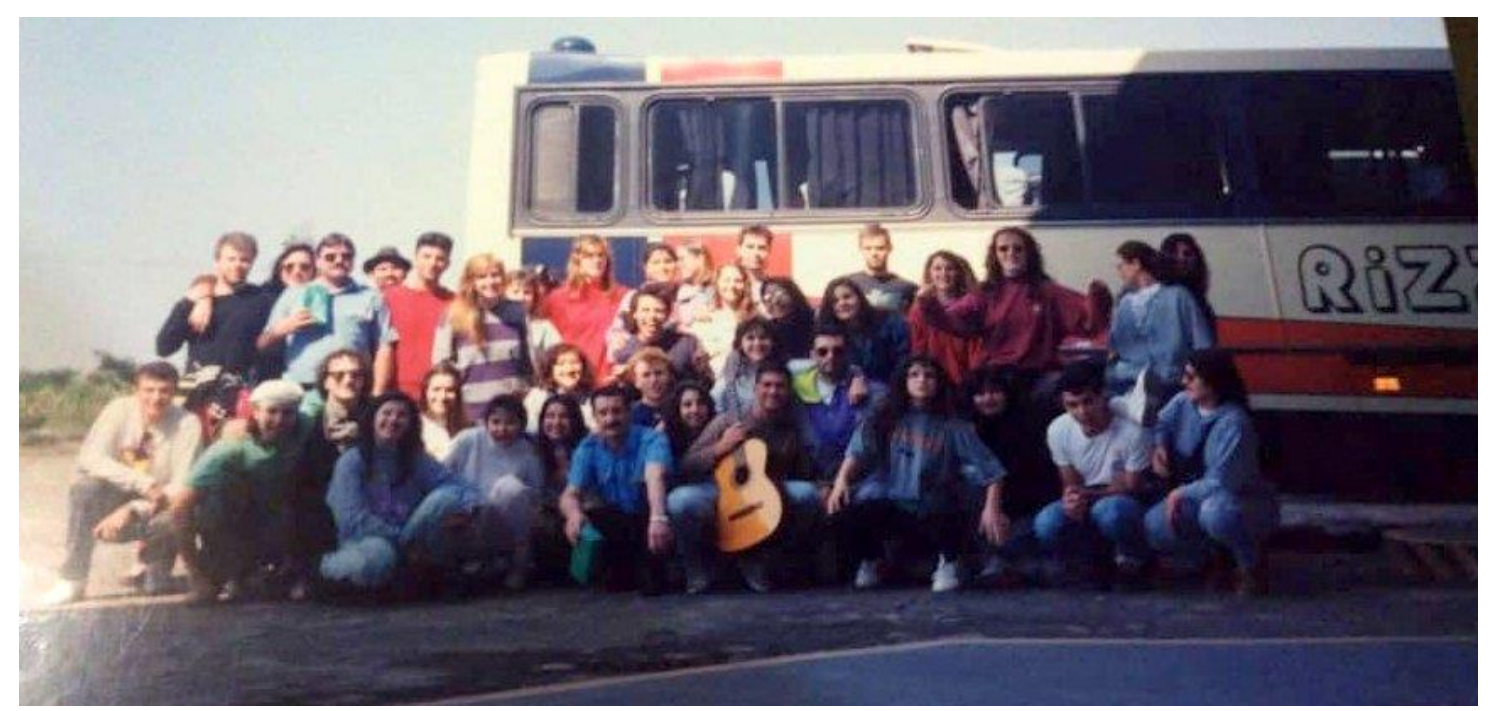

Fonte: Acervo pessoal das autoras 
Figuras 5 e 6: As autoras (uma abanando e a outra de chapéu) em uma das sessões do XIV ENEEF
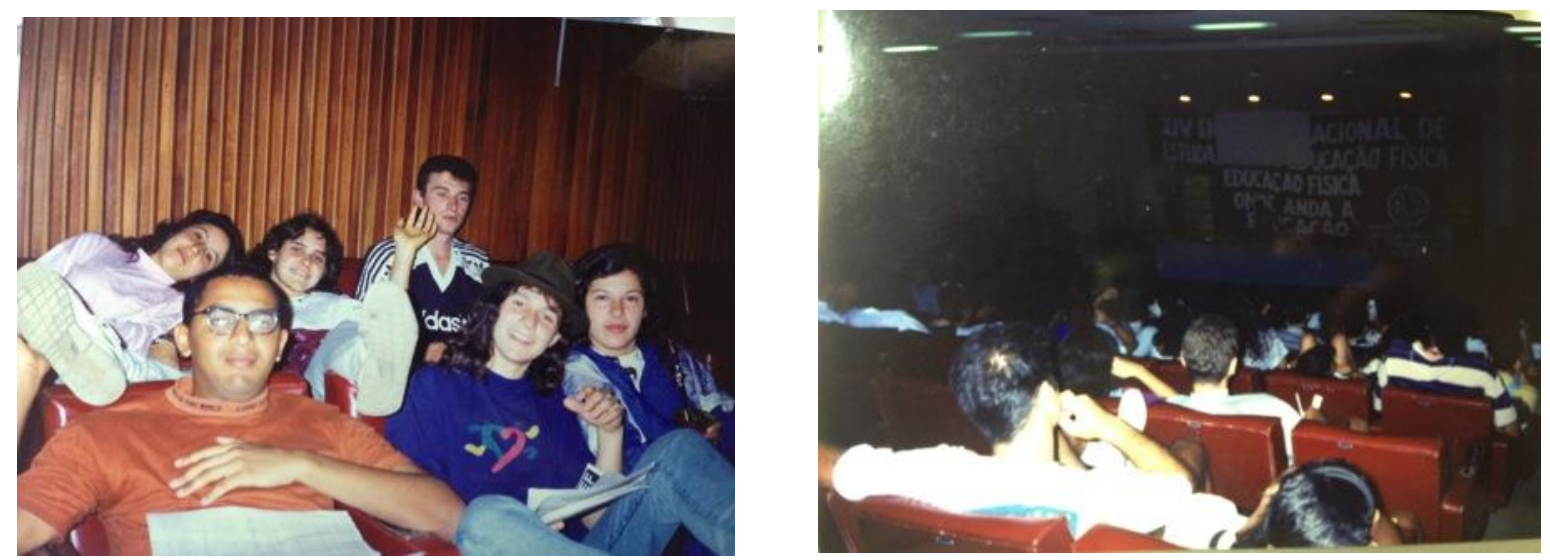

Fonte: Acervo pessoal das autoras

Tais encontros eram excelentes oportunidades para intercâmbio de culturas, discussões políticas e acadêmicas. Basta imaginar que a maioria destes estudantes nunca havia saído do Estado. Para o ENEEF da Paraíba foram percorridos de ônibus mais de 4.000km que separam Santa Maria de João Pessoa, passando por onze estados. Se antes já havíamos aprendido sobre as diferenças dentro do RS, agora um novo mundo de sotaques enriquecia nossa leitura do País. Para esta viagem em especial as negociações com a direção do CEFD foram intensas. Mesmo sendo em período de recesso entre primeiro e segundo semestre, pela distância o tempo de viagem necessário requeria que conseguíssemos liberação de mais uma semana que avançava no período de aulas. Os professores divergiam quanto a esta oportunidade: "Os alunos querem viajar só para se emaconharem”. Esse foi um dos argumentos ouvidos de um dos membros do conselho diretor, contra a liberação. A frase ficou gravada na memória porque foi anedótica, repetimos infinitamente durante a viagem, após conseguirmos a aprovação em meio a reuniões e argumentos que atestavam a seriedade de nossas intenções e os efeitos positivos desta formação.

Participamos ativamente do evento, um grupo com mais afinco, alguns nem tanto. Outros de fato sumiram pelas praias, tiveram insolação e aprenderam a dançar axé. Alguns relatam terem sido arrastados pela forte correnteza de uma das praias e se salvaram ao fazerem uma corrente humana. Não presenciamos a cena, mas certamente foi também um aprendizado. Ficamos nas dependências dos ginásios da Universidade Federal da Paraíba. Além de mesas e discussões, é fácil imaginar quanto aprendizado ao conversar com colegas de diferentes Estados, sobre a Educação Física, as diferentes disciplinas, sobre a cultura de modo geral. A falta de acesso à internet, facebook, instagram ou qualquer forma rápida de compartilhamento de informações fazia os encontros presenciais mais preciosos. Durante 
o evento ainda foi preciso negociar passagens de avião na reitoria da UFPB para transportar um dos estudantes que precisou ser internado em decorrência de sérios problemas de saúde. É provável que a maioria tenha dormido muito pouco durante a semana do evento, e a volta de quatro dias de viagem foi de um ônibus em completo silêncio. Na chegada o ônibus estacionou em uma das ladeiras próximas ao DCE e ao abrir o bagageiro rolaram cocos rua abaixo, souvenir precioso do Nordeste. Tenho certeza que muitas são as lembranças deste e de tantos outros eventos estudantis dos quais participamos. Deste ENEEF e do anterior, em Goiânia (Figura 7), lembramos vivamente das discussões fervorosas nas mesas, protagonizadas por expoentes da EF brasileira. Propositalmente eram convidados para compartilhar mesas docentes com posições opostas. Conhecemos assim posicionamentos e teorias diversas. Entre os mais fervorosos Celi Taffarel, Lino Castellani, Valter Bracht. Determinadas mesas eram sinônimo de briga certa e público garantido. O universo da Educação Física ampliou-se e ganhou outras cores. Participamos da Executiva Nacional (Figura 8) e representamos a Regional Sul, organizando um destes encontros da executiva em Santa Maria, no inverno, quando participantes de outros Estados aprenderam sobre o vento minuano e o frio do sul. Nestes eventos aprendemos sobre métodos de discussão: elaborar pauta, abrir inscrições para fala, "questão de ordem" e tantas outras nomenclaturas próprias deste dialeto dos debates infinitos até que alguém dizia "precisamos definir um teto" e "encaminhar proposições".

Figura 7: Crachás e material XIV ENEEF e XV ENEEF

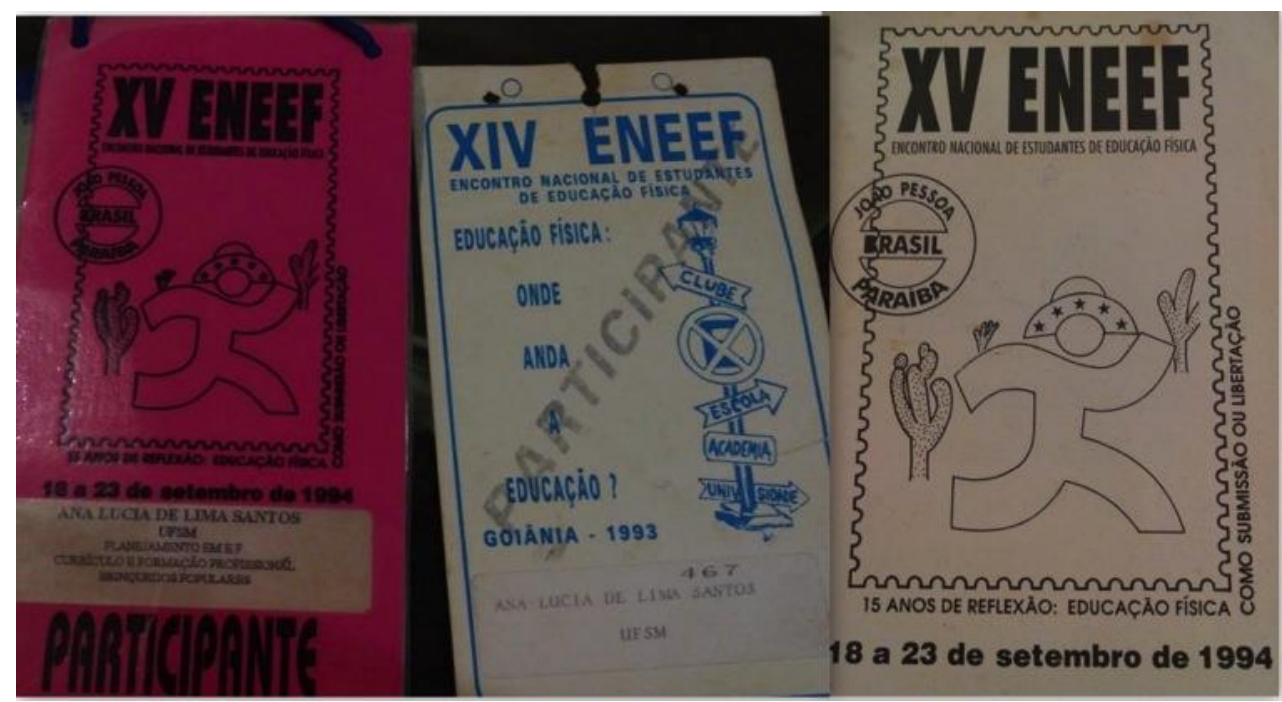

Fonte: Acervo pessoal das autoras 
Figura 8: Jornais da ExNEEF

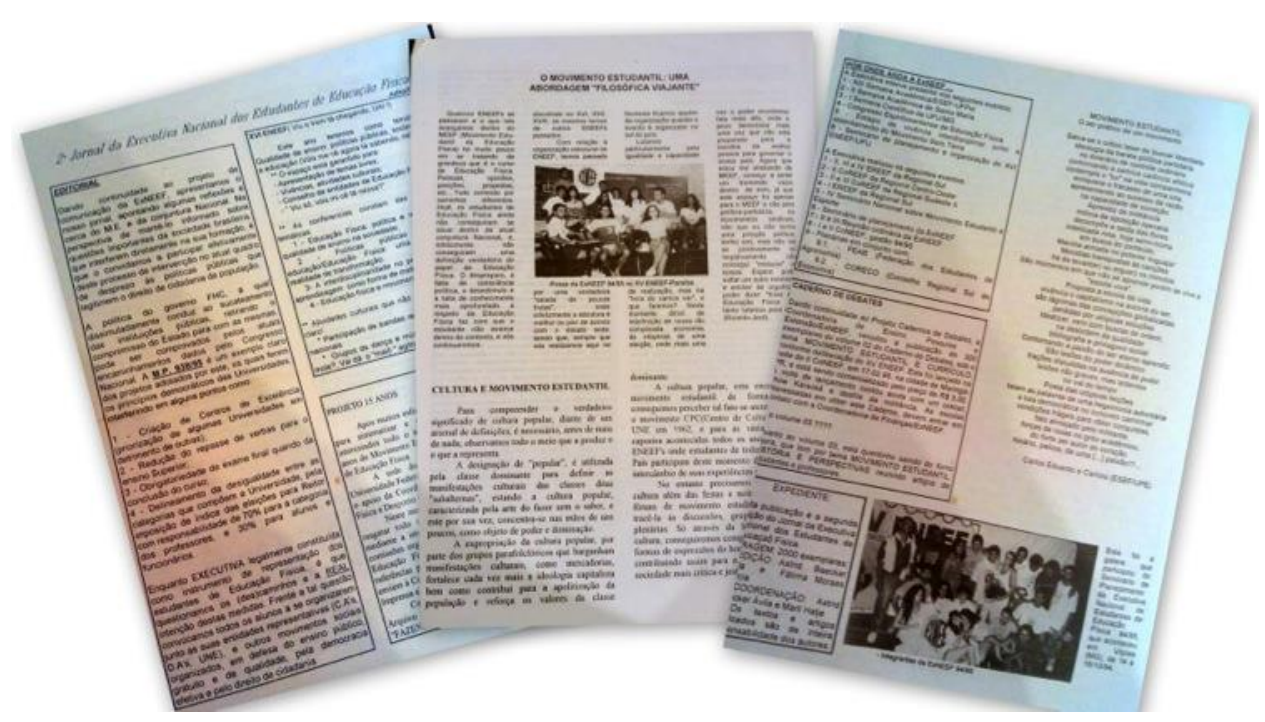

Fonte: Acervo pessoal das autoras

Também retomamos a organização dos Jogos Universitários, JUSM, por dois anos consecutivos. Após muitos anos de sua última edição apresentamos um projeto aos professores, propondo uma parceria. Em uma reunião da qual participamos nós duas, como representantes estudantis, e vários professores, homens obviamente, ouvimos que a proposta não tinha viabilidade. O evento era muito grande e exigia grandes responsabilidades. Mas, depois de muita argumentação e algumas reviravoltas, o DACEFD assumiu a organização do evento, com apoio do DCE e do CEFD, novamente sob a mira de um grande “eu avisei” caso algo "desse errado”. Quem é da área sabe o que significa organizar um grande evento esportivo, com competições de várias modalidades ao longo de dois ou três meses, das quais participaram aproximadamente dois mil estudantes. Nos jogos havia modalidades de esportes coletivos, individuais, natação, lutas e até truco. As negociações sobre local, arbitragem, equipamentos, entre tantos detalhes, foram exaustivas mas felizmente havia um grupo grande de estudantes envolvido. O ponto alto foi poder realizar as principais competições em espaços no centro de Santa Maria, ampliando assim a participação do público à noite e durante os finais de semana, pois o campus, em Camobi, era considerado longe e não tinha tanta circulação nestes horários. O requinte foi conseguir um plantão do Hospital Universitário disponível nos locais das principais atividades.

Outro evento importante neste período, de cunho mais científico, foi a realização de duas edições da Semana Acadêmica no CEFD (Figura 9). Convidávamos docentes da própria instituição e alguns externos, inclusive de fora do Estado, para palestras, mesas e workshops. A primeira edição foi a mais marcante, por ser a primeira e obviamente exigir muita negociação com a direção, mas também por ter 
uma paralisação do transporte público marcada para iniciar exatamente no primeiro dia do evento. Como mencionado, o campus principal fica no bairro de Camobi, aproximadamente $12 \mathrm{~km}$ distante da região central de Santa Maria, onde a maioria dos estudantes vivia naquela época. Também, no nosso curso especialmente, poucos estudantes tinham carro próprio. Para dar uma ideia, na minha turma de 50 colegas apenas um tinha esse privilégio. A Semana Acadêmica iniciaria na segunda-feira e a greve do transporte foi anunciada durante o final de semana. Sabíamos o impacto que isso poderia ter, e foram muitos os momentos de tensão quando decidimos manter a programação, principalmente considerando que a direção havia autorizado o evento se conseguíssemos manter mais de 50\% de estudantes participando. Segundo muitos professores, "estudantes não querem nada" e "irão debandar". Parece que certas frases soam como ecos, pois ainda escutamos afirmações parecidas nos corredores das instituições de ensino. Estávamos com tudo bem organizado, inclusive a impressão de anais, com resumos de trabalhos e palestras. Por falta de verbas a impressão se deu no próprio CEFD, em duas impressoras disponíveis, uma delas na direção, rodando o final de semana inteiro para garantir o material. Aquelas impressoras de "fita" em que as folhas eram conectadas em sequência e depois precisavam ser destacadas uma a uma. Além da tensão em saber se teríamos participantes no evento, na noite anterior a equipe passou acordada terminando os preparativos no local e acompanhando as impressoras, até que uma delas pegou fogo, literalmente. Justamente a da direção. Não lembro como resolvemos os problemas técnicos, provavelmente no melhor estilo Magaiver. Para nossa surpresa no dia seguinte o CEFD estava cheio de estudantes, a grande maioria deu um jeito de deslocar-se para as atividades programadas e a participação foi excelente, considerando as circunstâncias. Tais resultados nos permitiram realizar a edição seguinte, no próximo ano, sem a necessidade de tantos argumentos e um pouco mais de verba. O ponto alto eram as mesas sobre temas polêmicos e os minicursos, mas também o fato de termos pastas, material, anais e certificados personalizados para todas/os. Tivemos o apoio da direção, do DCE, mas também corremos a cidade em busca de patrocínios.

Foram muitos os eventos e manifestações, as reuniões eram infinitas, passávamos os dias inteiros na instituição, e prolongávamos atividades em noites no DCE. Nem todas as propostas foram bem sucedidas, muitas foram as decepções e provavelmente os equívocos. Inúmeras vezes saíamos arrasadas das reuniões com o conselho diretor e precisávamos retomar propostas até conseguir aprovação e apoio. Ao longo deste período muitos foram os panfletos e projetos elaborados, as discussões internas, os diálogos com docentes, as visitas à reitoria. Um grande aprendizado que ultrapassa o domínio de conteúdos curriculares. Um aprendizado político sobretudo de diálogo e reflexão. 
Figura 9: Material de divulgação e rascunho de charge para jornal - I e II Semana Acadêmica

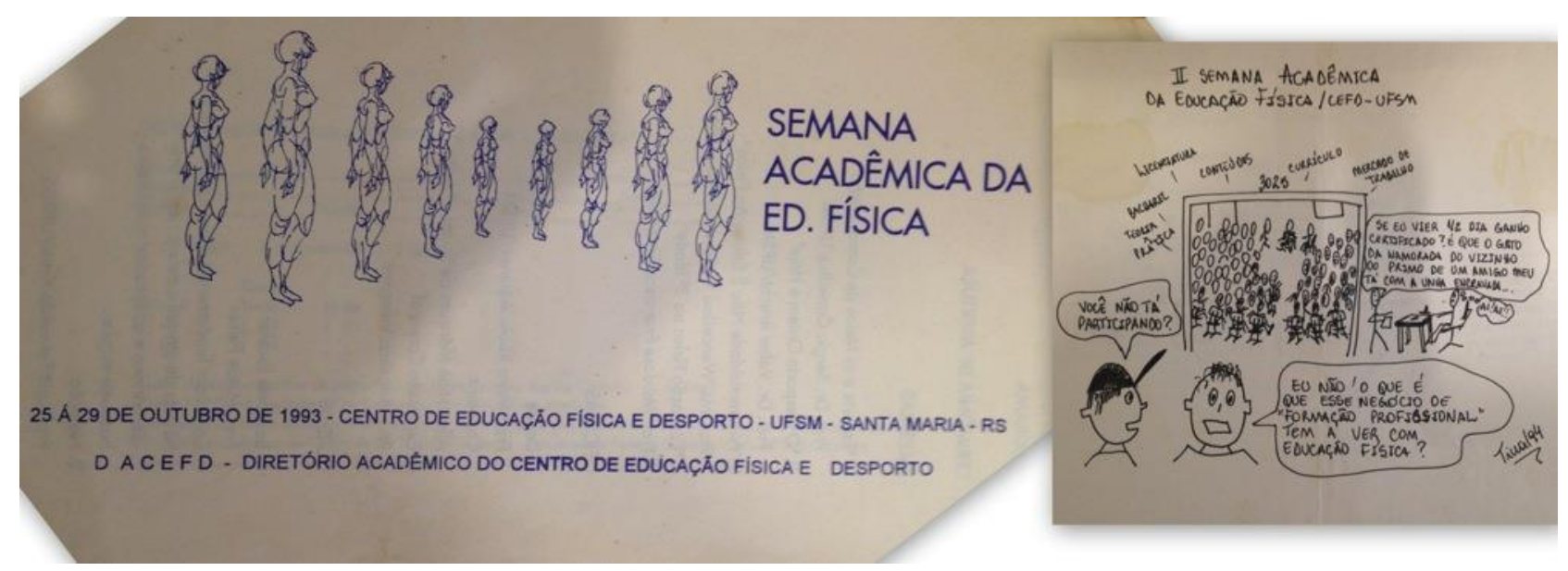

Fonte: Acervo pessoal das autoras

\section{Análise da experiência}

A motivação para este relato tem sido gestada há algum tempo, desde que se acirraram novamente as lutas pela universidade pública de qualidade. Pelo que acompanhamos da história recente de nosso país, desde o período em que estudamos na UFSM esta luta tem sido constante, mas com momentos de maior ou menor perigo. Nos anos 1990 víamos como destino quase certeiro a privatização. Posteriormente, com a mudança no âmbito federal, vivemos períodos de grandes investimentos nas universidade públicas. A UFSM ampliou seu campus, com novos cursos, prédios, investimentos na estrutura, permanência e mobilidade estudantil por meio de bolsas e outros recursos. Recentemente enfrentamos novamente sérias ameaças, tanto em termos de recursos como em relação à autonomia universitária. A educação é sempre política e os currículos, campo de disputas, estejamos conscientes ou não deste processo. A crítica à lógica de mercado e à conformidade que impregnam os sistemas de gestão da educação, bem como a análise acerca de suas consequências, está presente em muitos contextos há bastante tempo (GIROUX, 1997). O pensamento crítico e a participação democrática nos diferentes âmbitos pode nos auxiliar a assumir uma postura participativa consciente e responsável. Isso significa também um exercício de autonomia.

Muitas das pautas de nossas discussões estudantis se repetem, tanto no que diz respeito à defesa da universidade pública quanto em relação às especificidades da Educação Física. A recorrência dos problemas, que nos acompanham na atuação profissional em diferentes instituições de ensino público, 
traz uma sensação de lentidão ou mesmo fracasso. No âmbito do ME é fácil de entender esse processo, pois é feito por estudantes em formação, trata-se portanto de um movimento mais cíclico do que linear. A cada ano novos grupos entram e outros se formam e deixam a universidade. Pautas são alteradas e os avanços precisam ser reconquistados constantemente. Portanto é compreensível que a maior conquista é de fato o aprendizado político com esta experiência. Entretanto, há também um legado, que é o permanente estado de luta e conflito instaurado no interior da universidade. Este estado de luta alimenta os anseios democráticos e mantém a memória daquilo que defendemos. A curto prazo as conquistas parecem ínfimas, mas se pensarmos em tempos históricos os pequenos avanços multiplicam pegadas em nosso caminhar. Nem todas/os estudantes que participaram de debates e eventos seguiram defendendo o ensino público ou mesmo a universidade. Talvez as discussões não tenham sido profundas ou intensas o suficiente. Compartilhamos projetos, mas não necessariamente ideais.

Quando atuava como professora universitária em um curso particular reencontrei um antigo professor que, naquele momento aposentado da universidade pública, trabalhava no ensino privado. Havíamos participado de discussões nas quais ele efusivamente defendia a privatização sob os argumentos da qualificação de condições de trabalho. Ao nos encontrarmos novamente, agora como colegas, ele já havia mudado de opinião. Só queria um bom laboratório para trabalhar, mas o setor privado pouco investe em pesquisa. Atualmente trabalho na universidade pública e acompanho de perto a pressão sobre os cursos de formação de professoras/es para a compra de produtos pedagógicos em detrimento do investimento na autonomia e produção de conhecimento. A precarização da ciência e mercantilização da educação se consolidada a passos largos. Infelizmente poucos compreendem a importância da autonomia e a potência que podemos ser se apostamos em nossa capacidade de conhecer e criar. Falhamos no diálogo com a comunidade quando nos reduzimos a reprodutores de conhecimentos técnicos.

$\mathrm{Na}$ medida em que a situação política se deteriora pela falta de discussão qualificada e de responsabilidade, quando as pessoas não querem discutir questões sérias com profundidade superior aos mêmes do whatsapp, e sobretudo quando percebemos os ataques ao conhecimento e ao ensino público é grande o sentimento de que fracassamos no compromisso que assumimos com a educação. Assustador vivermos tempos em que se ouve falar de investigações realizadas pelo governo de atividades antifascistas entre professores, por exemplo. Histórias da ditadura, sobre as quais não discutimos devidamente, hoje nos perseguem e multiplicam seus resquícios (TELES; SAFATLE, 2010). Inacreditável pensar que pessoas com formação universitária, realizada em universidade pública, atacam o conhecimento e a autonomia, defendem a perseguição política e a tortura. Tais constatações são 
perturbadoras, mas não seriam surpreendentes se tivéssemos prestado mais atenção a nossa história. Como adverte Marc Bloch (2001, p.63), "a ignorância do passado não se limita a prejudicar a compreensão do presente; compromete, no presente, a própria ação”. O próprio ME preocupava-se com a compreensão histórica, conforme registrado em seus cadernos de debate, especialmente o volume três de 1995, com o tema "Movimento Estudantil: História e Perspectivas"1. Este caderno é resultado dos compromissos assumidos pela ExNEEF no XV ENEEF, em João Pessoa, período no qual fazíamos parte da Executiva. Na apresentação do volume, assinada por Maria do Carmo Morales Pinheiro (a "Carminha" da UFPel $)^{2}$, o tema justifica-se pelas opções que a história pode fornecer para a compreensão da realidade e subsidiar novas práticas. Em um dos textos, Guina reforça a importância da consciência histórica para o ME: "se somos capazes de relacionar os fatos históricos do passado com a realidade atual, então somos capazes de contribuir, de forma consciente, para que a história humana tenha um curso emancipador, e sei que este é o propósito do movimento estudantil de Educação Física.” (FERREIRA, 1995, p.36). Ainda assim, a julgarmos pela realidade atual, os esforços não foram suficientes.

Outro aspecto que causa tristeza é lembrar que os direitos das minorias não tinham centralidade, pouco falávamos sobre a representação de afro-brasileiros, homossexuais, sobre feminismo e outras questões presentes no cenário atual. Vivíamos em ambiente extremamente conservador, com muitos preconceitos explícitos em piadas e comportamentos machistas, racistas e homofóbicos, que assustadoramente se perpetuam. Vivíamos fortemente sob os resquícios de uma cultura de formação em Educação Física que separava turmas e conteúdos em femininos e masculinos. E, ainda hoje, muitas escolas têm aulas separadas por gênero e o debate acerca do tema é efervescente. Felizmente algum avanço se alcançou desde então em termos de consciência política e representatividade em relação a estes aspectos.

\section{Considerações finais}

A consciência histórica nos fortalece, nos situa enquanto sujeitos, nos permite maior profundidade em reflexões presentes. Assim, destacamos também a relevância deste número especial da Revista Kinesis, um periódico que acompanha a Educação Física brasileira desde 1984, fomentando os debates acadêmicos em sua pluralidade (GÜNTHER; DAMKE; LIMA, 2012). Entendemos que este periódico

\footnotetext{
${ }^{1}$ Os cadernos estão disponíveis no endereço digital da ExNEEF < https://exneefmeef.wixsite.com/exneef/cadernos-de-debate> e/ou no repositório digital/LUME da UFRGS <https://lume.ufrgs.br/>.

2 Até hoje para identificarmos colegas da ExNEEF precisamos lembrar dos apelidos, pois ninguém se conhecia pelo nome completo.
} 
torna-se também um valioso registro histórico, tanto para a área quanto para a Universidade. No que diz respeito aos estudos históricos em Educação Física e Esporte é interessante lembrar a atenção de Goellner (2012) para a impossibilidade de uma história no singular em um horizonte repleto de multiplicidades. Assim, registramos aqui nossa modesta contribuição, sabendo que compõe um cenário bastante amplo e complexo.

Entendemos que o curso de Educação Física no CEFD era excelente justamente porque oferecia muitas possibilidades, não só pela sua estrutura, disciplinas variadas e docentes qualificados, mas também pela oportunidade da diferença, do diálogo, da experiência do espaço público e democrático. E, para nós, é impossível refletir sobre nossa formação acadêmica sem considerarmos a atuação no DACEFD.

Muitas pessoas participaram desta história e não iremos citar nomes, tanto pelo receio de esquecer algum como pelo respeito ao anonimato. Foram muitas colegas que, por mais ou menos tempo, em situações específicas ou cotidianamente, conferiram profundidade e diversidade às discussões, trouxeram alegria e força para os embates, para as festas e encontros. Também aprendemos com docentes que se colocavam em diálogo, ou mesmo com aqueles que em conflitos nos tratavam com respeito. "Engolir sapos", "voltar atrás", "bater o pé”, "bater com a cabeça na parede”, "falar para as paredes”, "fazer cara de paisagem" são também movimentos corporais que fazem parte desta história.

Apesar de avanços questionáveis, possíveis equívocos e falhas, a participação no movimento estudantil foi intensa e trouxe, pessoalmente, um grande aprendizado: somos capazes de grandes conquistas, se formarmos coletivos, se compartilharmos projetos. Aprendemos inclusive com nossos erros, quando somos capazes de dialogar, ouvir, refletir.

\section{Referências}

ALMEIDA, M.F.R de. Política educacional brasileira na década de 1990: um desserviço à cidadania. Cadernos de História da Educação, n. 4, p.117-131, jan./dez. 2005.

BLOCH, M. Apologia da História ou o ofício de Historiador. Rio de Janeiro: Jorge Zahar, 2001.

FERREIRA, M.G. Movimento estudantil de Educação Física: em busca de raízes históricas. Uma breve reflexão. In.: Movimento Estudantil: história e perspectivas. Caderno de Debates. Executiva Nacional de Estudantes de Educação Física/ExNEEF. Coordenadoria de Ensino Pesquisa e Extensão. v.3, jul. 1995. Disponível em: https://lume.ufrgs.br/bitstream/handle/10183/106385/Volume3.pdf?sequence=1\&isAllowed=y Acesso em: 10 ago. 2020.

FREIRE, P. Pedagogia da autonomia: saberes necessários à prática educativa. São Paulo: Paz e Terra, 1996. 
GIROUX, H.A. Os professores como intelectuais: rumo a uma pedagogia crítica da aprendizagem. Porto Alegre: Artes Médicas, 1997.

GOELLNER, S.V. A importância do conhecimento histórico na formação de professores de Educação Física e a desconstrução da história no singular. Kinesis, Santa Maria, v. 30, n. 1, p.37-55, 2012.

GÜNTHER, M. C. C.; DAMKE, M. H.; LIMA, C. R. P. A trajetória da revista Kinesis: uma leitura a partir de seus editoriais. Kinesis, Santa Maria, v. 30, n. 1, p.8-23, 2012.

LE GOFF, J. História e memória. Campinas: UNICAMP, 1990.

SEDUFSM. Histórico de Greve. Seção Sindical dos Docentes da UFSM. Disponível em: http://www.sedufsm.org.br/?secao=greve Acesso em 10 ago. 2020.

SILVA, T. T. da (Org.); HALL, S.; WOODWARD, K. Identidade e diferença. A perspectivados estudos culturais. Petrópolis: Vozes, 2000.

SOUZA, M.S.; COUTO, M.L.; MARIN, E.C. A relação entre as ciências sociais e as ciências naturais na formação em Educação Física do CEFD/UFSM. Pensar a Prática, Goiânia, v. 17, n. 1, p.175-190, jan./mar. 2014.

TELES, E; SAFATLE, V. (Orgs.). O que resta da ditadura: a exceção brasileira. São Paulo: Boitempo, 2010.

UFSM. História da Educação Física - CEFD. Santa Maria, 2020. Disponível em: https://www.ufsm.br/cursos/graduacao/santa-maria/educacao-fisica/historico/ Acesso em: 10 ago. 2020.

\section{Como citar este artigo}

ZIMMERMANN, A. C; SANTOS, A. L. L. Aventuras estudantis no CEFD: sonhos, trajetórias e desencantos no diretório acadêmico. Revista Kinesis, Santa Maria, Dossiê CEFD 50 anos, p.01$17,2020$.

* O presente trabalho não contou com apoio financeiro de nenhuma natureza para sua realização. 